DOI: $10.20472 / \mathrm{IAC} .2017 .33 .034$

JONGOH KIM

Korea National Open University , Korea, Republic of

\title{
RACETRACK PUNTERS OVERPAY THE LOTTERY-TYPE STOCKS?
}

\begin{abstract}
:
The stock market has often been compared to gambling. Using daily return and volume data from January 1st, 2001 until December 31st, 2012 for all common shares listed on KOSPI and KOSDAQ in the Korea stock market, I examine the role of extreme positive returns in the cross-sectional pricing of stocks.

My argument rests on the idea that individual investors, like racetrack punters, overvalue assets with lottery-like payoff. Retail investors tend to hold poorly diversified portfolio and more susceptible to longshot bias than institutional investors. If individuals have stronger preference for lottery-type stock than institutions participating in the stock market, then stock return is related to the extreme events observed in the past, and investor overpay these stock with dreaming jackpot winners.

By testing several hypotheses, I find that individual investor overpay the lottery-type stocks. This investors' tendency increases gambling inclinations in market. Unlike previous studies, I find that racetrack punters do not tend to gamble during an economic downturn. Also, there is the strong intersection effect between maximum return portfolio and volatility, and between maximum return portfolio and skewness on the preference for gamble stocks. And, there are significantly stronger with lottery stock demanded by individuals than that of institutions.
\end{abstract}

\section{Keywords:}

Lottery-type stock, individual investor, price limit, maximum return portfolio

JEL Classification: G18, G11, G10 